\title{
La traducción alemán-español de los prospectos de medicamentos: análisis textual y terminológico
}

\author{
Isidoro Ramírez Almansa \\ Universidad de Córdoba \\ II2raali@uco.es \\ https://dx.doi.org.10.12795/futhark.2017.il2.08
}

Fecha de recepción: 10.07 .2017

Fecha de aceptación: 20.11.2017

Resumen: El presente trabajo aborda la traducción (alemán-español) del prospecto de medicamento como género textual dentro del ámbito de la traducción médica. Para ello, se ha estudiado su importancia dentro del sector farmacéutico y su valor tanto en el ámbito de la enseñanza como en el mercado laboral de la traducción. En primer lugar, se ha llevado un análisis de su macroestructura, $y$ en segundo lugar, se ha analizado, desde un punto de vista comparativo, su terminología y fraseología. Dicho análisis ha dado como resultado la creación de dos glosarios bilingües DE-ES, en el primero se recoge la terminología propia del prospecto, y en el segundo su fraseología. Los glosarios pretenden ser una herramienta didáctica, además de una herramienta profesional para aquellos que necesiten conocer y saber aplicar la terminología y fraseología del texto que nos ocupa.

Palabras clave: traducción médica; prospecto; terminología; fraseología; didáctica de la traducción.

\section{German-Spanish Translation of Package Leaflet: terminological and textual analysis}

\begin{abstract}
This paper focuses on the package leaflet translation (German-Spanish) as a textual genre in the field of medical translation. To this end, its importance within the pharmaceutical sector has been studied along with its value in the translation job market and the area of education. Firstly, the macrostructure has been analyzed. Subsequently, a comparative analysis of its terminology and phraseology has been carried out. As a result of such analysis, two bilingual glossaries DE-ES have been created, the first one recaps all the terminology extracted from the package leaflet, and the second one gathers its phraseology.
\end{abstract}


These glossaries intend to become an educational tool, as well as a professional tool for those who need to know and implement the terminology and phraseology of the mentioned text genre.

Key words: medical translation, package leaflet, terminology, phraseology, translation didactics.

Sumario: Introducción. I. Principales objetivos del proyecto y plan de trabajo. I.I. Objetivos generales. I.2. 0jetivos específicos. I.3. Fases de ejecución. 2. Resultados previsibles. Conclusiones.

\section{Introducción}

La independencia de la traducción médica, también denominada biosanitaria, como un ámbito independiente y no subordinado a la traducción científica y técnica es más que manifiesta. En sus orígenes recibió numerosas denominaciones como traducción biomédica (Vázquez 2006), traducción médico-sanitaria (Montalt y Shuttleworth 2012), traducción en el ámbito biosanitario (Félix y Ortega 1998), traducción biosanitaria (García y Varela 2009), traducción médico farmacéutica (Van Hoof 1970) o traducción biomédica y farmacéutica (Gouadec 2007). No obstante, ya por el año 1997 Navarro y Hernández le daba a este tipo de traducción un carácter autónomo. Navascues y Hernando (1998: 147-148) defendían que dicha independencia residía en el hecho de que "la traducción médica constituye un campo propio, con rasgos singulares que lo distinguen de otras parcelas [...] ya sean de orden científico o de otra naturaleza". Posteriormente, otros especialistas comparten también el mismo punto de vista, como Alarcón (1998: 1025) que defiende que este tipo de traducción tiene "un elemento temático significativo" o Montalt $(2009,2010)$ que recoge que la traducción biosanitaria "has some specific features that distinguish it from other types of translation”. Asimismo, Franco (2010: 157) añade como otro elemento a favor de esta postura que la práctica de la traducción biosanitaria exige un proceso formativo específico. Este argumento es a su vez compartido por Durieux (1998) y Mayor (2002).

Igualmente, esta separación entre traducción biosanitaria y científico y técnica queda doblemente corroborada al incluirse como tal en las aulas de las universidades españolas. Muñoz-Miquel (2016: 244) escribe que "las ya extinguidas licenciaturas de $\mathrm{TI}$ propiciaron la primera toma de contacto del alumnado con la traducción médica a través de las asignaturas de traducción científico-técnica, pero, por su naturaleza, no podían ofrecer una formación que se adecuara a las necesidades de los traductores especializados en medicina”. Con la llegada del Plan Bolonia en el curso académico 2010/20I I y la renovación de los planes de estudios de Traducción e Interpretación se incorporó la Traducción Biosanitaria a nivel 
grado como puede ser el caso de la Universidad de Córdoba, Rey Juan Carlos o Alfonso $X$ El Sabio, y con el paso del tiempo a nivel de máster en la Universidad Jaume I -aunque ya se impartía desde el año 2007- o la Universitat Pompeu Fabra. Además, habría que sumar las numerosas opciones de formación no contempladas en grado o máster como seminarios formativos, talleres, seminarios web, etc., que se imparten por parte de asociaciones, traductores especializados en este tipo de traducción, colegios de médicos o traductores profesionales.

El papel que la traducción biosanitaria desempeña en la actualidad tanto en el mercado profesional de la traducción, como en las aulas de las universidades es más que notable, su presencia en ambos contextos la convierte en una excelente opción para la formación o la especialización profesional. Lo que sirve como motivación para nuestro estudio que se centra, dentro de la gran amalgama que conforman los géneros textuales del ámbito biosanitario, en la traducción del prospecto analizando su terminología desde un punto de vista comparativo en español y alemán, así como su macroestructura.

\section{Géneros textuales de la traducción biosanitaria}

Al analizar la bibliografía disponible sobre el tema se demuestra cómo se ofrecen diversas clasificaciones de los géneros textuales que conforman la traducción biosanitaria atendiendo a diversos criterios. La más actual es la elaborada por Muñoz-Miquel (2016: 249) que distingue entre dos tipos de géneros prototípicos: en primer lugar, los prototípicamente médicos o exclusivos del ámbito (folleto de información para pacientes, prospecto médico, protocolo de ensayo clínico, vademécum, cuestionario de salud, etc.) y generados en el ámbito hospitalario (el macrogénero de la historia clínica que integra informe de urgencias, hoja de anamnesis, etc.) y en segundo los compartidos por más de un campo de especialidad (artículos originales, manuales, diccionarios, etc.).

Otros investigadores distinguen los denominados "sistemas de géneros", entendiendo estos como géneros interdependientes producidos en contextos comunicativos muy concretos y que a pesar de presentar divergencias entre sí, están relacionados, como es el caso de Yates y Orlikowski (2002) que reconocen estos sistemas enmarcados en la investigación médica o en el ámbito farmacéutico. Por otro lado, Montalt y González $(2007: 65,78)$ localizan la presencia del sistema de géneros dentro del campo de la investigación experimental con humanos - dando lugar a textos como el consentimiento informado o el protocolo de ensayo clínico- y la trasferencia de los resultados de dicha investigación con textos como los casos clínicos o los historiales médicos. Más cercano a nuestro objeto de estudio -el prospecto- Ezpelta (20I2) analiza el sistema de géneros del sector 
farmacéutico con textos como el prospecto, fichas técnicas de medicamente o resúmenes de características del mismo.

\section{I El prospecto como género textual}

En su trabajo, Muñoz-Míquel (2016: 249) presenta dos clasificaciones de los géneros textuales del ámbito biosanitario, la primera expuesta en el anterior punto de nuestro trabajo donde el prospecto ocuparía un lugar dentro del grupo de textos "típicamente médicos o exclusivos del ámbito". En la segunda clasificación siguiendo el concepto de sistema de géneros basado en los sectores de comunicación en los que se produce Muñoz-Miquel (2016: 250-255) divide los textos en seis grandes campos: farmacéutico, editorial, investigación, salud pública y atención sanitaria, instituciones europeas y empresas de traducción. La autora en su artículo detalla qué textos encontramos en cada sector y quién o quiénes los produce. Dado que el objeto de nuestro estudio es el prospecto, nos centraremos en el sector farmacéutico.

Muñoz-Miquel (2016: 250) considera que los géneros textuales recogidos en este sector son "muy variados y de distintos grados de especialización" y los clasifica en textos de contenido farmacéutico como prospectos, expedientes para el registro de medicamentos, manuales de aparatos diagnósticos etc., y textos derivados de la actividad empresarial habitual como memorias anuales, informes periódicos de resultados, comunicados de prensa, etc. La autora destaca que "el rasgo de destinatarios es variado: desde especialistas y autoridades sanitarias hasta pacientes y público general”.

El sector farmacéutico se encuentra en un estado de expansión continua, según Orf (2005) en el año 2005 ya representaba el 10, 4\% de la demanda empresarial de España. Según datos de PMFarma el valor del mercado de las prescripciones alcanzó durante el año 2016 los 9.695 millones de euros, lo que se traduce en unos I 530 millones de medicamentos vendidos. Estos datos ponen de relieve la importancia económica del sector farmacéutico centrado tan solo en la venta de medicamentos y obviando la financiación de I+D entre otros parámetros, lo que a su vez otorga al sector aún más valor.

Atendiendo a cómo las empresas a cargo de producir los medicamentos gestionan la traducción de sus productos, Hernández (1998) aseguraba que las empresas con mayor peso, por lo general, contaban entre su plantilla con una servicio de traducción interno que a su vez era asistido con colaboradores externos. Pero con el tiempo esta forma de trabajo cambió, Mayor et al (2004) confirman que ya la mayoría de los laboratorios no traducen sus productos con un servicio interno, sino externo, lo que ha provocado el auge de agencias y empresas 
dedicadas a este tipo de traducción como AltaLingua, okomeds o Traducciones Agora. Este modo de gestión por parte de las empresas sumaría otro motivo más por el cual el estudio del prospecto y su traducción da lugar a una mejor formación que redunda en una mejor preparación ante unas competencias y conocimientos que el mercado actual de la traducción demanda. De hecho, la traducción tiene reservado un lugar protagonista en este ámbito, ya que para conseguir unidad en las fichas técnicas, etiquetado, prospectos de nuevas autorizaciones y variaciones de medicamentos por procedimiento descentralizado y reconocimiento mutuo y en su traducción, la Agencia Española de Medicamentos y Productos Sanitarios (AEMPS) publicó ya en el año 201 lel presente documento en el que se describe un protocolo que debe seguir cualquier traducción de los textos anteriormente citados y que debe ser evaluada por la AEMPS y gestionada por el Titular de autorización de comercialización (TAC).

\section{Proceso de traducción del prospecto: macroestructura y terminología}

Hurtado Albir (200I) destaca que uno de los principales rasgos que diferencian los textos propios de un campo de especialidad frente a los textos de otros campos es la terminología presente en sus textos. Por ello, el prospecto no va a ser menos, y más aun dentro del ámbito biosanitario. A la hora de enfrentarse a este tipo de textos el traductor debe conocer a la perfección la terminología y debido a sus condiciones de trabajo entre las que impera el poco tiempo del que dispone para traducir y documentarse no es factible que pueda adquirir un buen dominio de la terminología a través de la lectura de libros u otro tipo de fuentes, ya que le exigiría un tiempo del que no dispone. Rouleau (1994:179) reitera que para evitar cualquier tipo de error en el campo de la traducción que nos ocupa, es indispensable conocer la terminología o la fraseología médica, así como saber utilizarlas. En lo que respecta al proceso de traducción de este tipo de textos, Muñoz-Miquel (2016: 255) identifica dos tipos de problemas como los principales a la hora de abordar su traducción: problemas temáticos, lingüísticos y terminológicos por un lado, $y$, en segundo lugar, problemas culturales.

Asimismo, Keller (20II: 235) en su artículo La traducción de textos médicos especializados, ilustrada mediante el par de idiomas inglés-alemán subraya que para el traductor de textos biosanitarios es de gran importancia que "estudie y adquiera el vocabulario especializado (la terminología). También es muy importante que trabaje bien las colocaciones (combinaciones de palabras) y la fraseología que, incorrectamente empeladas, lo delatan como no especialista.". De sus palabras se deduce que a pesar de la importancia que juega la terminología en otros campos de especialidad, en el campo biosaniatario lo es aún más, ya que un error en la terminología empleada puede tener consecuencias más que fatales, que pueden incluso poner en juego la vida de los pacientes, como ya demostraron Steiert y 
Steiert (20I I). Además, en este caso y en la combinación lingüística DE-ES internet tampoco es una fuente de recursos fiable, ya que según Keller (201 I: 235) “...los documentos médicos verdaderamente interesantes no son de uso público. En Alemania, concretamente, está prohibida la publicación de estos documentos, por lo cual el acceso a las correspondientes bases de datos está reservado al personal médico asistencial”.

Este contexto hace que el traductor de textos biosanitarios DE-ES encuentre dificultades en el proceso documental. Por este motivo la existencia de estudios dedicados a la creación de recursos terminológicos ES-DE en el campo biosanitario es más que necesaria. Estos recursos son igualmente demandados en el ámbito educativo, ya que son necesarios en el proceso de formación de los futuros traductores profesionales.

\section{I Análisis de la macroestructura}

Al analizar la estructura del prospecto médico es necesario hacerlo considerándolo casi como un texto jurídico, no por su contenido, sino por el hecho de que está sujeto a una normativa que regula todas y cada una de sus partes, si bien lo hacemos, como es nuestro caso y dado nuestro campo de actuación más próximo, dentro de la Unión Europea. La normativa europea que regula la distribución, comercialización de los medicamentos, así como estandariza y normativiza el prospecto son la Directiva 200I/83/CE y la Directiva 2004/27/CE publicada tres años más tarde y que modifica a la primera Directiva. Ambas recogen los requisitos que cada país debe reunir, dejando en manos de cada país cómo hacerlo y todo ello con el firme objetivo de establecer "un código comunitario sobre medicamentos para uso humano". En este punto de nuestro trabajo es necesario también hablar de la Agencia Europea de Medicamentos (EMA) que se trata de una agencia de la UE descentralizada fundada en 1995 con los siguientes fines:

I. Facilitar el desarrollo de los medicamentos y su acceso a ellos

2. Evaluar las solicitudes de autorizaciones de comercialización

3. Hacer el seguimiento de la seguridad de los medicamentos a lo largo de todo su ciclo de vida

4. Proporcionar información a los profesionales sanitarios y los pacientes.

Dentro del marco de la EMA nace el Working Group on Quality Review of Documents (QRD) o Grupo de la Agencia Europea de Medicamentos para la revisión de la calidad de los documentos con los siguientes objetivos: asegurar la claridad en el uso de la lengua, así como la precisión en la información que se 
ofrece en el envasado y los prospectos de medicamentos, verificar la consistencia de la información del medicamento en su traducción a otras lenguas, ofrecer un texto que cumpla unos estándares de legibilidad, llevar a cabo una tarea de revisión y actualización de cualquier cambio que se necesario realizar en cualquier medicamento bajo la indicación de la UE y contribuir a la implementación de una legislación que regule la información que debe acompañar a cada medicamento, así como las directrices para su envasado. El QRD en el año 2014 publicó un documento titulado Compilation of QRD decisions on stylistics matters in product information en el que se indicaban una serie de directrices ortográficas $y$ ortotipográficas que debe seguir cualquier documento que aporte información de un medicamento, regulando desde el uso de abreviaturas, formato de fechas o unidades de medida. Asimismo, el QRD ofrece una serie de documentos que establecen las directrices que se debe seguir a la hora de redactar cualquier documento relacionado con el medicamento, no solo el prospecto, sino también textos como el resumen de las características del producto, su ficha técnica, de la que forma parte el prospecto junto al etiquetado, etc. No obstante, es importante poner de relieve que ya en el año 2009 la Comisión Europea publicó un documento bajo el título Guideline on the Readability of the Labelling and Package Leaflet of Medicinal Products for Human Use en el que se indicaban un número de requisitos que debía reunir el prospecto de medicamentos con el fin de asegurar un mínimo grado de legibilidad, regulando aspectos como el estilo, la sintaxis, el color o los encabezamientos entre otros muchos.

Dado que nuestro objeto de estudio es el prospecto, en esta ocasión nos centraremos en cómo debe ser este género textual (Packungsbeilage en alemán) y qué estructura debe seguir. Para ello, analizaremos el documento publicado por la EMA Ficha técnica o resumen de las características del producto en el que se detalla cómo debe procederse a la redacción de la ficha técnica o resumen de las características del producto, a la vez que se explica cómo de presentarse el texto del etiquetado, y del género que nos ocupa, el prospecto. En esta ocasión, nos centraremos el análisis de su macroestructura, en el que ofrecemos aquellas anotaciones consideramos relevantes para la traducción.

La macroestructura del prospecto de medicamento según el QRD es:

\section{Prospecto: información para el <paciente><usuario>}

\section{\{Denominación (de fantasía) dosis forma farmacéutica\}}

$$
\text { \{Principio(s) activo(s)\}' }
$$

\footnotetext{
1 En el encabezamiento se debe utilizar la misma forma para nombrar al medicamento, ya sea la denominación común o de fantasía, además del principio activo, su concentración y forma farmacéutica. 
<Este medicamento está sujeto a seguimiento adicional, lo que agilizará la detección de nueva información sobre su seguridad. Puede contribuir comunicando los efectos adversos que pudiera usted tener. La parte final de la sección 4 incluye información sobre cómo comunicar estos efectos adversos.>

$<$ Lea todo el prospecto detenidamente antes de empezar a <tomar $><$ usar $>$ este medicamento, porque contiene información importante para usted.

- $\quad$ Conserve este prospecto, ya que puede tener que volver a leerlo.

- Si tiene alguna duda, consulte a su $<$ médico $><,><0><$ farmacéutico $><0$ enfermero>.

Este medicamento se le ha recetado solamente a usted, y no debe dárselo a otras personas aunque tengan los mismos síntomas que usted, ya que puede perjudicarles.>

- $\mathrm{Si}$ experimenta efectos adversos, consulte a su <médico>, $<,><0><$ farmacéutico $><0$ enfermero $>$, incluso si se trata de efectos adversos que no aparecen en este prospecto². Ver sección 4.

<Lea todo el prospecto detenidamente antes de empezar a <tomar><usar> este medicamento, porque contiene información importante para usted ${ }^{3}$.

$<$ Siga exactamente las instrucciones de administración del medicamento contenidas en este prospecto o las indicadas por su $<$ médico $><,><0><$ farmacéutico $><0$ enfermero>.

- Conserve este prospecto, ya que puede tener que volver a leerlo.

- Si necesita consejo o más información, consulte a su farmacéutico.

- Si experimenta efectos adversos, consulte a su $<$ médico $><,><0><$ farmacéutico $><0$ enfermero $>$, incluso si se trata de efectos adversos que no aparecen en este prospecto. Ver sección 4.

- Debe consultar a un médico si empeora o si no mejora <después de \{número de\} días>.>

\section{Contenido del prospecto}

I. Qué es X y para qué se utiliza

2. Qué necesita saber antes de empezar a <tomar $><$ usar $>X$

3. Cómo <tomar $><$ usar $>X$

En el resto del prospecto no es necesario, cuando se hace referencia al medicamento, indicar de nuevo la dosis y forma farmacéutica. En cuanto al formato y la forma de expresión de la dosis debemos seguir las indicaciones de la EMA recogidas en el documento.

${ }^{2}$ Esta sección se dedica a los medicamentos que se obtienen solo con receta.

${ }^{3}$ Esta sección se dedica a los medicamentos que se pueden obtener sin receta. 
4. Posibles efectos adversos

5. Conservación de $X$

6. Contenido del envase e información adicional

I. Qué es $X$ y para qué se utiliza ${ }^{4}$

$<$ Debe consultar a un médico si empeora o si no mejora <después de \{número de\} días>.>

\section{Qué necesita saber antes de empezar a $<$ tomar $><$ usar $>X^{5}$}

No $<$ tome $><$ use $>X<$ : $>$

$<$ si es alérgico al (a los) \{principio(s) activo(s)\} o a alguno de los demás componentes de este medicamento (incluidos en la sección 6$)^{6}$.>

\section{Advertencias y precauciones}

Consulte a su médico $<0<<,><$ farmacéutico $><0$ enfermero $>$ antes de empezar a $<$ tomar $><$ usar $>X$

\section{Niños <y adolescentes. $>$}

Otros medicamentos $\mathbf{y} \mathbf{X}^{7}$

$<$ Uso $><$ Toma $>$ de $X$ con otros medicamentos < lnforme a su $<$ médico $><0><$ farmacéutico $>$ si está<tomando $><$ utilizando $>, \quad$ ha $<$ tomado><utilizado> recientemente o pudiera tener que <tomar $><$ utilizar $>$ cualquier otro medicamento.>

\section{$<$ Uso $><$ Toma $>$ de $X$ con $<$ alimentos $><y><,><$ bebidas $><y><$ alcohol $>$}

\section{Embarazo $<y><$, $>$ lactancia $<y$ fertilidad $>$}

$<$ Si está embarazada o en periodo de lactancia, cree que podría estar embarazada o tiene intención de quedarse embarazada, consulte a su

$<$ médico $><0><$ farmacéutico $>$ antes de utilizar este medicamento. $>$

\footnotetext{
${ }^{4}$ En este apartado se recoge el grupo farmacoterapéutico o el tipo de actividad, además de las indicaciones terapéuticas.

${ }^{5}$ En este apartado se ofrece la información previa que necesita saber quien toma el medicamento. Suele contener indicaciones relacionadas con la edad o una población especial de pacientes.

${ }^{6}$ En esta sección se indica con detalle cualquier advertencia o precaución que se debe tomar ante la toma del medicamento de acuerdo al RCP (Resumen de las Características del Producto o Ficha técnica).

${ }^{7}$ En esta sección se ofrece información sobre las interacciones relacionadas con otros medicamentos y no relacionadas con otros medicamentos. Asimismo, se indica bajo qué circunstancias debe tomarse el medicamento: antes o durante las comidas, con o sin alimentos, etc.
} 


\section{Conducción y uso de máquinas ${ }^{8}$ $<$ X contiene \{nombre del (de los) excipiente(s) $\}^{9}$}

\section{Cómo <tomar $><$ usar $>\mathbf{X}^{10}$}

<Siga exactamente las instrucciones de administración de este medicamento indicadas por su médico <o farmacéutico $>$. En caso de duda, consulte de nuevo a su $<$ médico $><0<<$ farmacéutico $>$.

$<$ La dosis recomendada es... $>$

$<$ Siga exactamente las instrucciones de administración del medicamento contenidas en este prospecto 0 las indicadas por su $<$ médico $><,><0<<$ farmacéutico $><0$ enfermero $>$. En caso de duda pregunte a su $<$ médico $><0><,><$ farmacéutico $><0$ enfermero.>

$<$ La dosis recomendada es...>

\section{<Uso en niños <y adolescentes>>}

$<$ La ranura sirve únicamente para partir el comprimido si le resulta difícil tragarlo entero.>

$<$ El comprimido se puede dividir en dosis iguales.>

$<$ La ranura no debe utilizarse para partir el comprimido.>

\section{Si $<$ toma $<<$ usa $>$ más $X$ del que debe ${ }^{\prime \prime}$}

\section{<Si olvidó <tomar > usar > X>}

$<$ No tome una dosis doble para compensar las dosis olvidadas. $>$

\section{$<$ Si interrumpe el tratamiento con $X>^{12}$}

\footnotetext{
${ }^{8}$ En esta sección se informa sobre la capacidad de conducir o utilizar máquinas.

${ }^{9}$ En esta sección se informa sobre los excipientes que contiene el medicamento y que son importantes para un uso correcto y seguro del mismo.

${ }^{10}$ En este apartado se informa de cómo tomar y administrar el medicamento. Puede ir acompañado de ilustraciones si son de utilidad. También aquí se indica si el medicamento ha de tomarse con alimentos, antes o durante las comidas, y se informa sobre la posible influencia de alimentos o bebidas. Asimismo, se indica la frecuencia de administración del medicamento. En caso de ser un medicamento sin receta debe indicarse la duración media del tratamiento, la duración máxima, los intervalos del tratamiento y los casos en los que se debe acortar.

" En esta sección se describe cómo reconocer si se ha ingerido una sobredosis y qué se debe hacer.
} 
$<$ Si tiene cualquier otra duda sobre el uso de este medicamento, pregunte a su $<$ médico $><$, $>\langle 0\rangle\langle$ farmacéutico $><$ o enfermero $>$. $>$

\section{Posibles efectos adversos ${ }^{13}$}

Al igual que todos los medicamentos, este medicamento puede producir efectos adversos, aunque no todas las personas los sufran.

\section{<Otros efectos adversos en niños <y adolescentes >>}

\section{Comunicación de efectos adversos}

$\mathrm{Si}$ experimenta cualquier tipo de efecto adverso, consulte a su $<$ médico $><0<<$, $><$ farmacéutico $><0$ enfermero $>$, incluso si se trata de posibles efectos adversos que no aparecen en este prospecto. También puede comunicarlos directamente a través del sistema de notificación incluido en el Apéndice $V$ sistema nacional de notificación incluido en el Apéndice $V^{*}$. Mediante la comunicación de efectos adversos usted puede contribuir a proporcionar más información sobre la seguridad de este medicamento.

\section{Conservación de $\mathbf{X}^{14}$}

Mantener este medicamento fuera de la vista y del alcance de los niños.

No utilice este medicamento después de la fecha de caducidad que aparece en $<\mathrm{la}$ etiqueta $><$ la caja $><$ el frasco $><\ldots><$ envase $><$ después de \{abreviatura de la fecha de caducidad\}. $><$ La fecha de caducidad es el último día del mes que se indica. $>$ $<$ No utilice este medicamento si observa \{descripción de indicios visibles de deterioro\}.>

$<$ Los medicamentos no se deben tirar por los desagües <ni a la basura>. Pregunte a su farmacéutico cómo deshacerse de los envases y de los medicamentos que ya no necesita. De esta forma, ayudará a proteger el medio ambiente.>

\footnotetext{
12 En esta sección se describe qué debe hacer la persona que ingiere el medicamento tras una toma irregular del mismo.

${ }^{13}$ En este apartado se indica los efectos adversos que puede producir el medicamento. También se indica, si es necesario, qué medidas se deben tomar.

14 En este apartado se informa sobre la fecha de caducidad del medicamento y las condiciones de conservación.
} 


\title{
6. Contenido del envase e información adicional ${ }^{15}$
}

\section{Composición de $\mathbf{X}$}

- $\quad$ El (los) principio(s) activo(s) es (son)...

- $\quad$ Los demás <componentes $><$ (excipientes) $>$ son...

\section{Aspecto del producto y contenido del envase}

Titular de la autorización de comercialización y responsable de la fabricación ${ }^{16}$

\{Nombre y dirección\}

$<\{$ Teléfono $\}>$

$<\{$ Fax $\}>$

$<$ e-mail>

Pueden solicitar más información respecto a este medicamento dirigiéndose al representante local del titular de la autorización de comercialización ${ }^{17}$ :

\section{België/Belgique/Belgien \\ $\{\mathrm{Nom} / \mathrm{Naam} / \mathrm{Name}\}$ \\ $<$ Adresse/Adres/Anschrift $\}$ \\ B-0000 \{Localité/Stad/Stadt $\}>$ \\ Tél/Tel: $+\left\{\mathrm{N}^{\circ}\right.$ de \\ téléphone/Telefoonnummer/ \\ Telefonnummer\} \\ $<$ e-mail $>$}

\section{България \\ \{Име \\ $<\{$ Адрес $\}$ \\ $\{Г р а д\}\{$ Пощенскикод $\}>$}

\author{
Lietuva \\ \{pavadinimas\} \\ $<\{$ adresas $\}$ \\ LT \{paštoindeksas $\}$ \{miestas $\}>$ \\ Tel: +370 \{telefononumeris\} \\ $<$ e-mail >
}

15 En este apartado se indica cualitativa y cuantitativamente el/los principio(s) activo(s) recogidos en la $\mathrm{RCP}$. Al igual que se detallan los excipientes que componen el medicamento.

\begin{abstract}
${ }^{16}$ En esta sección si coincide el titular de la autorización de comercialización y el responsable de la fabricación se agrupan en un mismo título. Es necesario antes de indicar el nombre de cualquiera de las dos figuras anteponer el título que ostenta. Si existe más de un responsable de fabricación debe reflejarse en el documento, aunque en cada lote solo se indicará el responsable de la fabricación que lo ha producido.

17 En esta sección no es necesario incluir la lista de representantes locales, pero si se incluye, deben recogerse todos. Además, un país puede tener más de un representante local o este puede coincidir con el TAC.
\end{abstract}




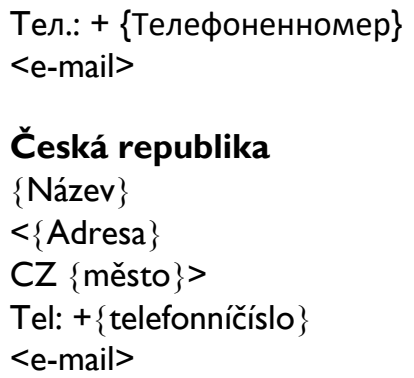

\section{Eesti}

(Nimi)

$<$ (Aadress)

EE - (Postiindeks) (Linn)>

Tel: +(Telefoninumber)

$<$ e-mail>

\section{$E \lambda \lambda \alpha \dot{\alpha} \delta \alpha$}

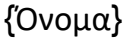

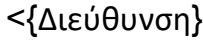

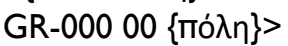

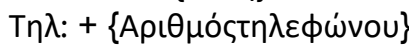

$<$ e-mail $>$

\section{España}

\{Nombre\}

$<$ Dirección $\}$
téléphone/Telefonnummer\}

$<$ e-mail>

\section{Magyarország}

$\{$ Név\}

$<\{$ Cím $\}$

$\mathrm{H}-0000$ \{Város\}>

Tel.: +Telefonszám\}

$<$ e-mail>

\section{Malta}

\{lsem\}

$<\{$ Indirizz $\}$

MT-0000 $\{$ Belt/Raћal $\}>$

Tel: $+\{$ Numrutat-telefon $\}$

$<$ e-mail>

\section{Nederland}

$\{$ Naam $\}$

$<\{$ Adres $\}$

NL-0000 XX \{stad $\}>$

Tel: $+\{$ Telefoonnummer $\}$

<e-mail>

\section{Norge}

\{Navn\}

$<$ Adresse $\}$

$\mathrm{N}-0000$ \{poststed $\}$

TIf: $+\{$ Telefonnummer $\}$

$<$ e-mail $>$

\section{Österreich}

\{Nombre\}

$<\{$ Anschrift $\}$

A-0000 \{Stadt $\}>$

Tel: + \{Telefonnummer $\}$

$<$ e-mail>

\section{Polska}

\{Nazwa/ Nazwisko:\}

$<\{$ Adres: $\}$ 


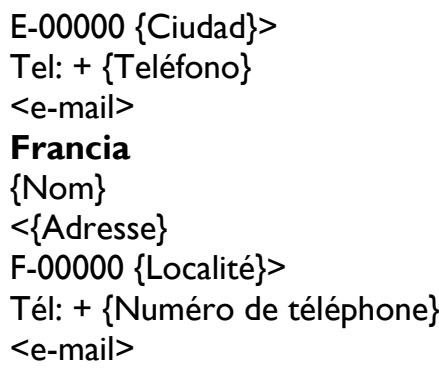

\section{Hrvatska}

\{lme\}

$<\{$ Adresa $\}$

\{Poštanskibroj\} \{grad\}>

Tel: $+\{$ Telefonskibroj\}

$<$ e-mail $>$

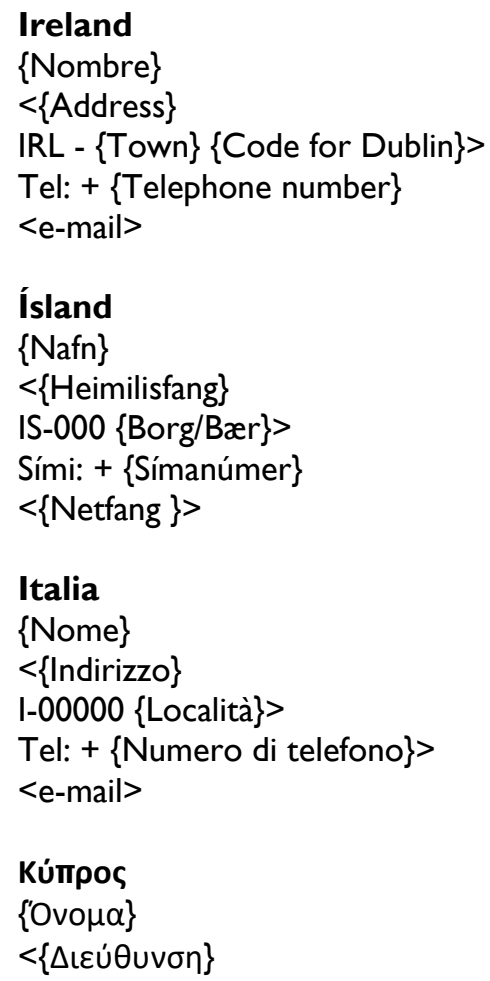

Italia

\{Nome

$<\{$ Indirizzo $\}$

I-00000 \{Località $>$

Tel: $+\{$ Numero di telefono $\}$ $<$ e-mail $>$

\section{Kúmpos}

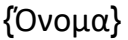

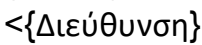

PL -00 000\{Miasto: $\}>$

Tel.: $+\{$ Numertelefonu: $\}$

$<$ e-mail>

Portugal

\{Nome\}

$<\{$ Morada $\}$

P-0000 $\square 000$ \{Cidade $\}$

Tel: $+\{$ Número de telefone $\}$

$<$ e-mail>

\section{România}

\{Nume\}

$<\{$ Adresă $\}$

\{Oraș\} \{Cod poștal\} - RO>

Tel: $+\{$ Număr de telefon $\}$

$<$ e-mail $>$

\section{Slovenija}

\{Ime\}

$<\{$ Naslov $\}$

SI-0000 \{Mesto $\}>$

Tel: + \{telefonskaštevilka\}

$<$ e-mail>

\section{Slovenská republika}

$\{$ Názov $\}$

$<$ Adresa $\}$

SK-000 00 \{Mesto $>$

Tel: $+\{$ Telefónnečíslo $\}$

$<$ e-mail>

\section{Suomi/Finland}

\{Nimi/Namn\}

$<\{$ Osoite/Adress $\}$

FIN-00000 \{Postitoimipaikka/Stad $\}>$

Puh/Tel: +

\{Puhelinnumero/Telefonnummer\}

$<$ e-mail>

Sverige

$\{$ Namn\}

$<\{$ Adress $\}$ 


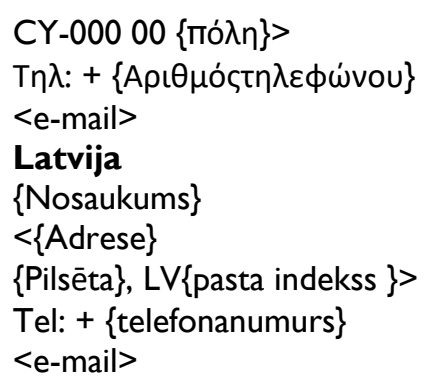

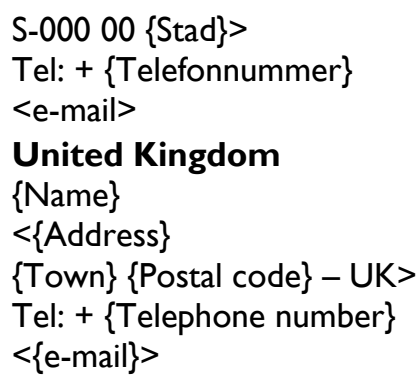

Fecha de la última revisión de este prospecto: $<\{M M / A A A A\}><$ mes AAAA $\}>$.

<Este medicamento se ha autorizado con una «aprobación condicional». Esta modalidad de aprobación significa que se espera obtener más información de este medicamento.

La Agencia Europea de Medicamentos revisará la información nueva de este medicamento al menos una vez al año y este prospecto se actualizará cuando sea necesario.>

<Este medicamento se ha autorizado en «circunstancias excepcionales». Esta modalidad de aprobación significa que <debido a la rareza de su enfermedad><por motivos científicos $><$ por razones éticas $>$ no ha sido posible obtener información completa de este medicamento.

La Agencia Europea de Medicamentos revisará anualmente la información nueva de este medicamento que pueda estar disponible y este prospecto se actualizará cuando sea necesario.>

\section{$<$ Otras fuentes de información $>^{18}$}

La información detallada de este medicamento está disponible en la página web de la Agencia Europea de Medicamentos: http://www.ema.europa.eu/ <, y en la página web de la \{Agencia Española de Medicamentos y Productos Sanitarios (AEMPS)\} (http://www.aemps.gob.es/)\}>. <También existen enlaces a otras páginas web sobre enfermedades raras y medicamentos huérfanos. ${ }^{19}>$

A continuación ofrecemos un ejemplo real de prospecto (comprimidos de paracetamol I g de la farmacéutica Aristo), en el que podemos ver cómo su prospecto cumple cada uno de los requisitos que recoge el QRD. También

\footnotetext{
${ }^{18}$ El título de esta sección no aparece como tal en la versión del prospecto en español o alemán, sino que directamente comienza con el texto.

${ }^{19}$ Se añade esta aclaración solo en el caso de medicamentos huérfanos.
} 
ofrecemos un prospecto en alemán (gotas de codeína $30 \mathrm{mg}$ de la farmacéutica Tryasol(, con los requisitos que se presentan en el QRD.

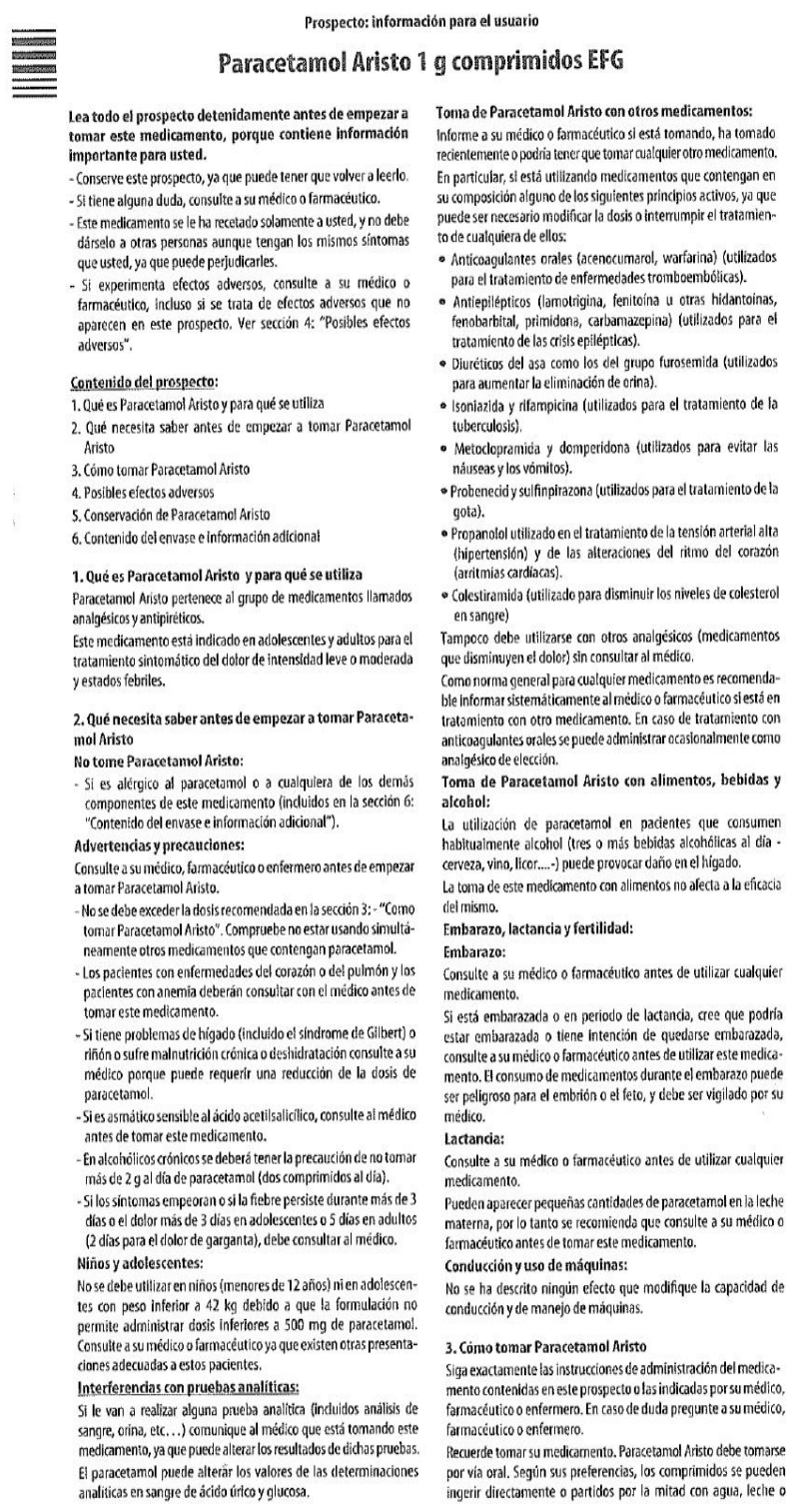


zumo def frutass. Los comprimidos están ranuradoss, lo que pernite

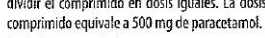

La dosis recomendada es:

Adultos: mediso 1 comprimida (1 a de paractatamali) 3-4 veces a dia. Las tomas deben essaciarse al menos 4 horas. No se tomarán más de 4 comprimidos ( 4 g) en 24 horas.

Uso an niñosy adolescentes:

- Adolescentes mayores de 15 años (Deso superior a $50 \mathrm{~kg}$. segutiren la posooggia de aculuttos.

Acalescenties a partir de 12 anosypeso superior a 42 kgy pueden tomar medio comprimido por toma (cada 4 - 6 llorass),

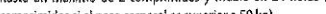

Este meditanento no es adeciado para niños (ver sección 2:

Testicoreato oeten tomian intervalo mínimo entre cada toma de 8 borars. No deben toma mäs de 2 gramas de paractamol en 24 horss, eppartidos en 2 tomas

- Pacientes con enfermeddades del liñón. antes de tomar este medicarnerito tienen que consultar a su méd ô.

Debentomar como máximo 500 miligrannos por toma.

Pacientes de edad dyanzada: deben consuliar a su médico.

La admininstración del medicamento estás supeditatala la a aparicion

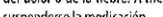

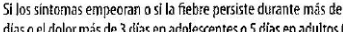
dias para el delor de garganta) debe consultar a l médice.

Si se essitima oue ia acciōn de este meditamento s denasiado fuerte o débil, comuniqueselio a su mético o farmacéutition. Si toma más Paracetamol Aristo del que deble:

Si usted tia tomado mas Paracetamol de io que debe, consulte

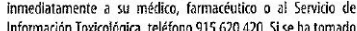
Información Toxiccógigia, teléf́ono 915620420 . Si se hatomado
una sobredosis debe audiri inmediatamente a un centro médico una sobredosis, debe acudiri inmediatamente a un centro medico
aungue no hatya sintonas, ya que a menudo no se manificstar

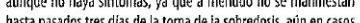

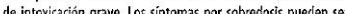

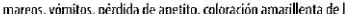
piel y los ojos (ictericia) y dotor abdominal. El trataniento de la sobredossises más eficazsis seinicia dentro de las 4 horas siguientes ala tomadel medicamento.

Los padientes en tratamiento con barbituturicos o que padezan àcoholisma crónico pueden ser más susceptibles a tna sobredossis

etanol Aristo

No tome una ciosis deble para compensar las dosis olvidadas,

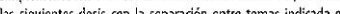
cadacase (al menos 4 horas'.

4. Posibles efectos adverso medicamentos, Paracetamol Aristo puede produciri feet tos adverescos, aunctue no todas las perschas los sulfan. Paracetamol Aristo puede producir los siguientes efectos adversos: - Raros (pueden afectar liasta a I de cada 1.000 pacientes):

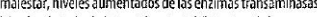

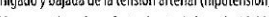

- Muy raros (puedern afecter liasta 1 de cada 10.000 pacientes) reacciones alergicas (como erropciones de la piell), bjajada de piel), alterationes en el tinónon, crina turbia
Se han notificado muy raramente casos de reacciones graves en

Comunicación de efectros atversos

experimente cualquier tipo de efecto adverso, consulte a su médito o farmacéutico, inclisso si se trata de posilibes efectos adversos que no aparecen en el prospecto. Tantibién pued Farmacovisilancia de medicmentos de Iso Humano: hitps

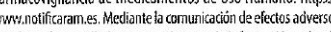
puete contribuir a proporcionar más información sobre seguridad die este medicamento.

5. Conservación de Paracetamol Aristo

Mantenereste medicamento fuer te le v visia y det atkante de los iños Este medicamento no requiere conciciones espectales de conservacion.

No utilice este meticanento después de la fecha dè caduturida que aparece en el envase después de CAD, ta fecha de cadtectho es el uiltimo día del mes que se indica.

los meeticamentos no se deben tirar por los tesagües ni a a las su farmatice camentos que na necesita. De esta forma, ayudará a proteger medil ambient

6. Contenido del envase e información adicional

Composidión de Paracetanol hristo:

El prisipipio active es paracetamiol.

los demás componentes son: almituón pregelatinizzalo de me

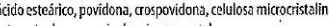

Aspecto del producto y contenido del envase:

Pararetantel Aristo se presenta en forma de compinimidos obiongos, de color blanco y ranurados por una de sus caras, min-PYC-PYOC

tular de Ther de ta antoin:

Titular:

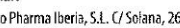

28850, Torejejón de Ardoz: Madtid. España

Responsable de la fabricadón:

Advance Phartia GimbH

Wallenroder Staßape 12:71

13435 Berlin, Alemania

Fecha del a uiltima revisión deeste prospecto (1)

Otras fuentes de información

La informaciön detallada y y actualizacta de este medicmanteo est

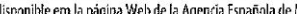
mentosy y Productos Sanitarios (AEMPS
hittp://www. aemps. gob.esi

Imagen I: Prospecto español 
Gebrauchsinformation: Information for Anwender

ACC $600 \mathrm{mg}$ tabs

Tablezten

Acotyloystein

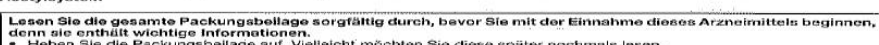

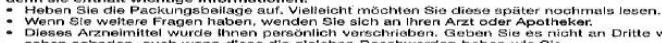

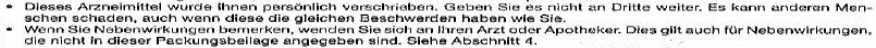

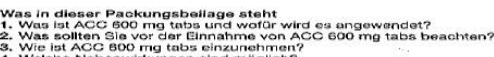

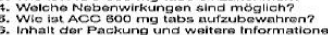

HEXAL

1 WaE Ist ACC 600 mg fabs und worar

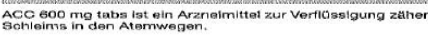

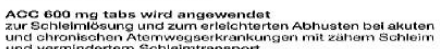

2 Was soluten sie vor der Einnatwine von

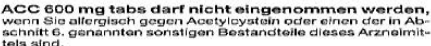

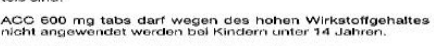

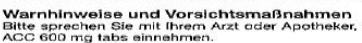

werden, Iragen Sie vor der Einn
ren Arzt oder Apotheker um Ra

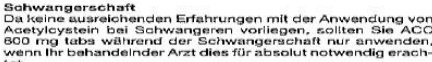

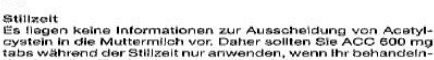

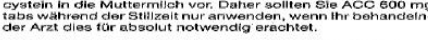

Verkehrstüchtigkeit und Fähigkeit zum Bedienen Es sind keine Desonderheiten zu beachten.

ACC 600 ing tabs enthalt Lactose und Natriumver-

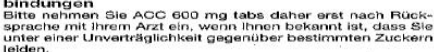

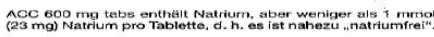

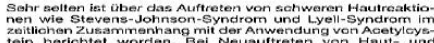

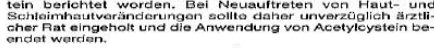

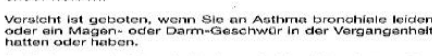
3 Wic ist ACC soo mg tabs einzuneh-
men?

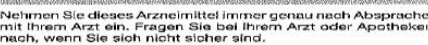

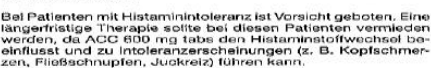

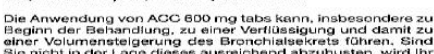

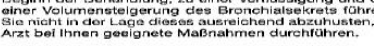
Einnahme von ACC 800 mg tabs zusammen mit an-

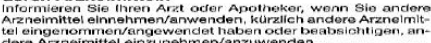
Woohsolwirkungestudien wurden nur bel Erwachsenen dures-
gofiunrt. Anttisuslva (huastonstillendo Mittel)

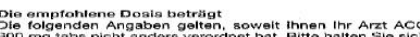

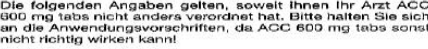

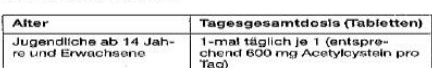

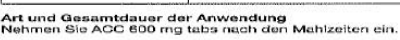
Die Tablette kann in gleiche Dosen getellt werden.

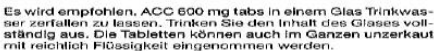

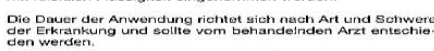

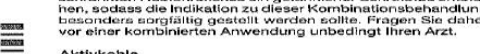
Aktivkohle
Dotivanvondung vo
oystoin vorringern.

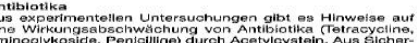

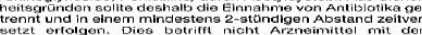

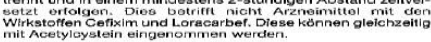

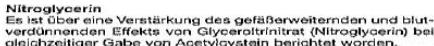

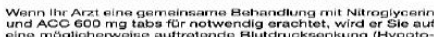

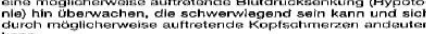

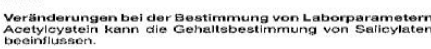

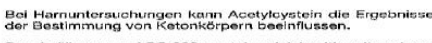

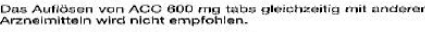

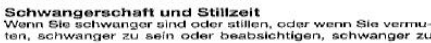

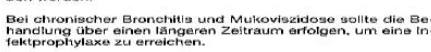
Wenn Sie eine größere Menge von ACC $600 \mathrm{mg}$

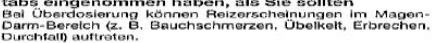

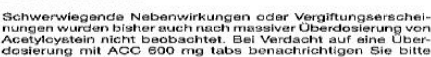
Wenn Sie die Einnahme von ACC $600 \mathrm{mg}$ tabs ver

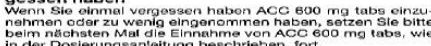
Wenn Sie die Einnatme von ACC $600 \mathrm{mg}$ tabs ab-

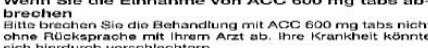

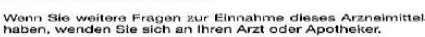
4. Wortho Nabonwirkungan sind mos-

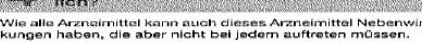
Bel den Hautigkeitsangaben zu Nebenwirkungen werden foFortsetzung aur der Rackselte > 


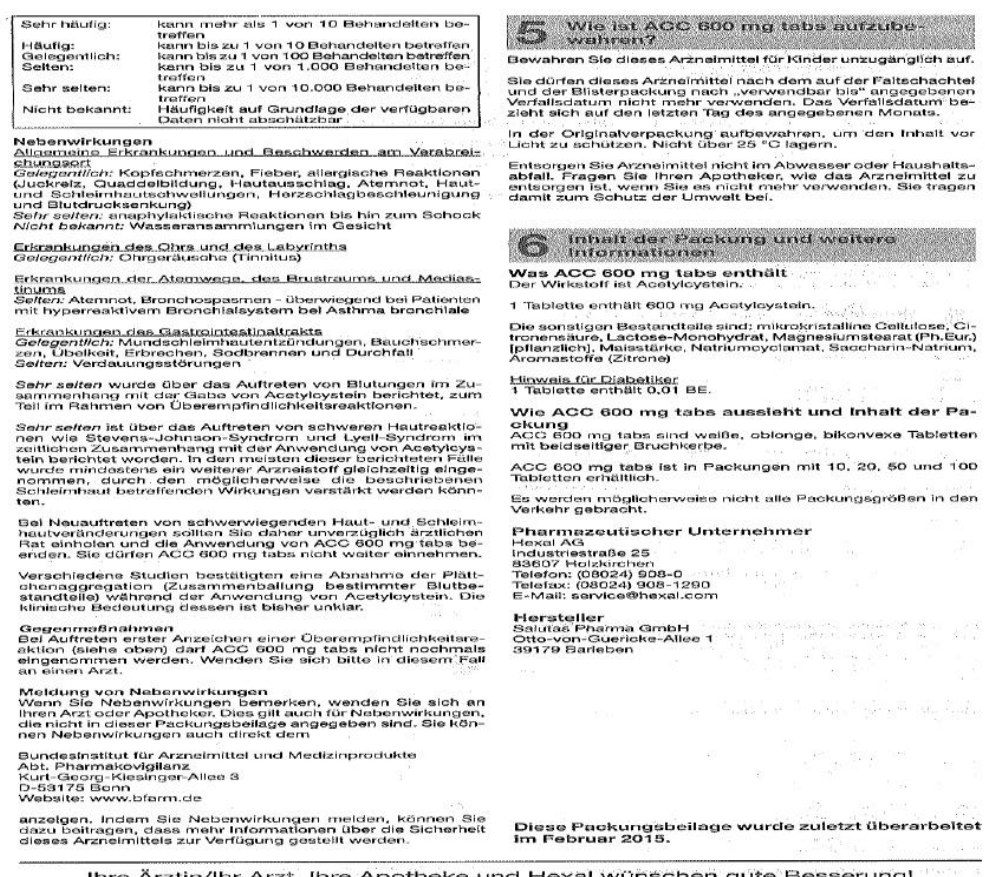

Imagen 2: Prospecto alemán 


\subsection{Análisis terminológico y fraseológico DE-ES}

Como ya hemos demostrado, el buen dominio de los términos y fraseología del campo biosanitario por parte del traductor y el hecho de saber cómo utilizarla es una de las principales competencias que debe poseer. Keller (20ll: 235) en su trabajo investiga cuál es la mejor forma para el traductor de aprender y adquirir esta terminología, y para ello parte de la hipótesis de investigar cómo lo hacen los estudiantes de medicina, es decir, personas sin un conocimiento previo pero que al fin de su etapa de formación conocen y hacen un buen uso de la terminología biosanitaria. Con este fin Keller analiza los registros de bibliotecas y planes de estudio de medicina de universidades de EE UU y Alemania encontrándose con títulos como Medical Terminology for Health Professionals, Medical Terminology Simplified, Fachsprache Medizin im Schnellkurs, Fachsprache Medizin leicht gemacht e incluso Medical Terminology for Dummies. En el análisis de las obras la autora determina que la mayoría de ellas siguen el mismo esquema de organización, ofreciendo los términos o unidades de significación especializada (USE) a modo de tabla junto a su definición, lo que es de gran utilidad para el traductor. Las obras estadounidenses tienden a ofrecer glosarios monolingües, $y$ las obras alemanas, por lo general, ofrecen glosarios bilingües con el término en alemán, en inglés y su definición. Dado que los prospectos presentan su propia fraseología y terminología propia a continuación elaboraremos, como si de un manual para aprender terminología biosanitaria se tratase, un glosario bilingüe DE-ES recogido en diversas tablas, con la definición del término, en caso de que sea necesario debido su alto nivel de especialización o al considerarla importante para diferenciar ese término respecto a otros, el término en alemán, su traducción al español y un campo denominado comentarios para la traducción, en el que se aporta información sobre la traducción del término y sobre qué aspectos debemos tener en cuenta en dicho proceso. Por otro lado, y como segunda parte de nuestro análisis, 


\begin{tabular}{|c|c|}
\hline \multicolumn{2}{|l|}{ DE } \\
\hline ES & $\begin{array}{l}\text { Agencia Española de Medicamentos y Productos Sanitarios } \\
\text { (AEMPS) }\end{array}$ \\
\hline Definición & $\begin{array}{l}\text { Agencia estatal adscrita al Ministerio de Sanidad, Consumo } \\
\text { y Bienestar Social, es responsable de garantizar a la } \\
\text { sociedad, desde la perspectiva de servicio público, la } \\
\text { calidad, seguridad, eficacia y correcta información de los } \\
\text { medicamentos y productos sanitarios, desde su } \\
\text { investigación hasta su utilización, en interés de la } \\
\text { protección y promoción de la salud de las personas, de la } \\
\text { sanidad animal y el medio ambiente. Fuente: AEMPS } \\
\text { https://www.aemps.gob.es/laAEMPS/presentacion/home.htm }\end{array}$ \\
\hline $\begin{array}{l}\text { Comentario para } \\
\text { la traducción }\end{array}$ & $\begin{array}{l}\text { En la versión alemana del prospecto no se ofrece } \\
\text { información relativa a la agencia que regula la revisión de } \\
\text { los prospectos, sino que tan solo se indica la última fecha } \\
\text { de revisión. }\end{array}$ \\
\hline
\end{tabular}

\begin{tabular}{|l|l|}
\hline DE & Anwendung \\
\hline ES & uso \\
\hline $\begin{array}{l}\text { Definición } \\
\text { la traducción }\end{array}$ & $\begin{array}{l}\text { En su traducción en este contexto al español sufre una } \\
\text { transposición y se tiende a la verbalización del sustantivo } \\
\text { Anwendung traduciéndose por usar. }\end{array}$ \\
\hline
\end{tabular}

\begin{tabular}{|l|l|}
\hline DE & Arzneimittel \\
\hline ES & medicamento \\
\hline $\begin{array}{l}\text { Definición } \\
\text { Organismo que, administrada interior o exteriormente a un } \\
\text { enfermedad y corregir o reparar las secuelas de esta. } \\
\text { la traducción }\end{array}$ & $\begin{array}{l}\text { Fuente: DRAE https://dle.rae.es/?id=OkljC3R } \\
\text { on el prospecto no se utiliza la denominación sinónima de }\end{array}$ \\
\hline
\end{tabular}




\begin{tabular}{|l|l|}
\hline DE & $\begin{array}{l}\text { Arzneimittel Überwachung } \\
\text { unterzuliegen }\end{array}$ \\
\hline Definición & $\begin{array}{l}\text { Medicamentos sujeto a seguimiento adicional } \\
\text { intensivo que los demás medicamentos. Generalmente ello } \\
\text { se debe a que se dispone de menos información sobre } \\
\text { estos medicamentos que sobre otros, por ejemplo porque } \\
\text { se trata de un medicamento comercializado recientemente } \\
\text { o porque la información de la que se dispone sobre su uso } \\
\text { a largo plazo es limitada. No significa que el medicamento } \\
\text { sea menos seguro. } \\
\text { https://www.aemps.gob.es/vigilancia/medicamentosUsoHum } \\
\text { ano/seguimiento adicional.htm\#med ssa }\end{array}$ \\
\hline Comentario para \\
la traducción
\end{tabular}

\begin{tabular}{|l|l|}
\hline DE & Behandlung \\
& medicamento huérfano \\
\hline Definición & $\begin{array}{l}\text { Productos medicinales destinados al diagnóstico, } \\
\text { prevención o tratamiento de enfermedades que ponen en } \\
\text { riesgo la vida, o muy graves o enfermedades que son raras. } \\
\text { Fuente: EURORDIS-Rare Diseases Europe } \\
\text { https://www.eurordis.org/es/content/\%C2\%BFque-es-un- } \\
\text { medicamento-huerfano }\end{array}$ \\
\hline $\begin{array}{l}\text { Comentario para } \\
\text { la traducción }\end{array}$ & $\begin{array}{l}\text { En el prospecto no se utiliza la denominación sinónima de } \\
\text { origen latino existente en alemán Medikament. }\end{array}$ \\
\hline
\end{tabular}

\begin{tabular}{|l|l|}
\hline DE & Beschwerde \\
\cline { 2 - 2 } ES & síntoma \\
& $\begin{array}{l}\text { Manifestación reveladora de una enfermedad. Fuente: } \\
\text { DRAE https://dle.rae.es/?id=Y00ZvBC }\end{array}$ \\
\hline $\begin{array}{l}\text { Comentario para } \\
\text { la traducción }\end{array}$ & $\begin{array}{l}\text { Su traducción literal sería molestia o dolor, pero en español } \\
\text { la convención en este contexto es síntoma }\end{array}$ \\
\hline
\end{tabular}

Futhark I2 (2017) 


\begin{tabular}{|l|l|}
\hline DE & Bestandteil \\
\cline { 2 - 2 } ES & excipiente \\
& $\begin{array}{l}\text { Sustancia inerte que se mezcla con los medicamentos para } \\
\text { darles consistencia, forma, sabor u otras cualidades que } \\
\text { faciliten su dosificación y uso. Fuente: DRAE } \\
\text { https://dle.rae.es/?id=TujIWIL }\end{array}$ \\
\hline $\begin{array}{l}\text { Comentario para } \\
\text { la traducción }\end{array}$ & \\
\hline
\end{tabular}

\begin{tabular}{|c|c|}
\hline DE & $\begin{array}{l}\text { Bundesinstitut für Arzneimittel und Medizinprodukte Abt. } \\
\text { Pharmakovigilanz, Kurt-Georg-Kiesinger-Allee 3, D-53175 } \\
\text { Bonn, Website: www.bfarm.de (Das nationale } \\
\text { Meldesystem) }\end{array}$ \\
\hline ES & $\begin{array}{l}\text { Sistema Español de Farmacovigilancia de Medicamentos de } \\
\text { Uso Humano: https://www.notificaram.es } \\
\text { (sistema nacional de notifiación) }\end{array}$ \\
\hline Definición & $\begin{array}{l}\text { Órganos nacionales de cada país a los que el usuario del } \\
\text { medicamento debe comunicar cualquier efecto adverso que } \\
\text { no aparezca reflejado en el prospecto. Fuente: propia. }\end{array}$ \\
\hline $\begin{array}{l}\text { Comentario para } \\
\text { la traducción }\end{array}$ & $\begin{array}{l}\text { En cada idioma se ha reflejado la forma exacta en la que } \\
\text { debe aparecer en el prospecto cada sistema nacional de } \\
\text { notificación. }\end{array}$ \\
\hline
\end{tabular}

\begin{tabular}{|c|c|}
\hline DE & Darreichungsform \\
\hline ES & Dosis farmacéutica \\
\hline Definición & $\begin{array}{l}\text { Disposición individualizada a que se adaptan las sustancias } \\
\text { medicinales (principios activos) y excipientes para } \\
\text { constituir un medicamento. Fuente: Vanesa Ferrandis Tébar } \\
\begin{array}{l}\text { Especialista en } \\
\text { http://cofsegovia.portalfarma.com/Documentos/Curso\%20Fi }\end{array} \\
\text { sioterap\%C3\%A9utas/3.- } \\
\text { \%20FORMAS\%20FARMAC\%C3\%89UTICAS\%20Y\%20V\%C } \\
\text { 3\%8DAS\%20DE\%20ADMINISTRACI\%C3\%93N.pdf }\end{array}$ \\
\hline $\begin{array}{l}\text { Comentario para } \\
\text { la traducción }\end{array}$ & \\
\hline
\end{tabular}




\begin{tabular}{|c|c|}
\hline DE & Doppelte Menge \\
\hline ES & dosis doble \\
\hline Definición & $\begin{array}{l}\text { En alemán para expresar el concepto de dosis doble no se } \\
\text { emplea el equivalente del término dosis en español (Dosis), } \\
\text { sino que se expresa a través de la palabra Menge (cantidad) } \\
\text { quedando Doppelte Menge. }\end{array}$ \\
\hline $\begin{array}{l}\text { Comentario para } \\
\text { la traducción }\end{array}$ & \\
\hline
\end{tabular}

\begin{tabular}{|l|l|}
\hline DE & Dosis \\
\hline ES & dosis \\
\hline Definición & $\begin{array}{l}\text { Cantidad de fármaco que se administra para el tratamiento } \\
\text { de una enfermedad. Fuente: Enciclopedia médica y } \\
\text { terminología } \\
\text { (https://www.diccionariomedico.net/diccionario- } \\
\text { terminos/645I-dosis }\end{array}$ \\
la traducción para & $\begin{array}{l}\text { En el contexto del prospecto dos palabras en alemán se } \\
\text { traducen de la misma forma en español, como es el caso de } \\
\text { Stärke y Dosis que ambas se traducen por dosis. En el } \\
\text { segundo caso, el término se refiere según la Enciclopedia } \\
\text { médica y terminología médica a la cantidad de fármaco que } \\
\text { se administra para el tratamiento de una enfermedad. } \\
\text { (https://www.diccionariomedico.net/diccionario- } \\
\text { terminos/645I-dosis) }\end{array}$ \\
\hline
\end{tabular}

\begin{tabular}{|l|l|}
\hline $\begin{array}{l}\text { DE } \\
\text { ES }\end{array}$ & Einnahme \\
Definición & $\begin{array}{l}\text { Cada una de las veces que se administra un medicamento } \\
\text { por vía oral. Fuente: DRE } \\
\text { https://dle.rae.es/?id=ZzNW207 }\end{array}$ \\
\hline $\begin{array}{l}\text { En su traducción en este contexto al español sufre una } \\
\text { la traducción }\end{array}$ & $\begin{array}{l}\text { transposición y se tiende a la verbalización del sustantivo } \\
\text { Einnehmen traduciéndose por tomar. }\end{array}$ \\
\hline
\end{tabular}




\begin{tabular}{|c|c|}
\hline DE & Die Europäische Arzneimittel-Agentur \\
\hline ES & Agencia Europea del Medicamento \\
\hline Definición & $\begin{array}{l}\text { Se creó el I de Enero de } 1995 \text { bajo los auspicios del } \\
\text { Reglamento EEC } \mathrm{N}^{\circ} 2309 / 93 \text {. Inicialmente denominada } \\
\text { Agency for the Evaluation of Medicinal Products, en mayo } \\
\text { de } 2004 \text { cambió su denominación por la actual bajo los } \\
\text { auspicios del Reglamento EC } N^{\circ} 726 / 2004 \text {. A pesar del } \\
\text { cambio de denominación el acrónimo permanece } \\
\text { inalterado. Fuente: Asociación Española de Derecho } \\
\text { Farmacéutico } \\
\text { https://www.actasanitaria.com/fileset/doc_40I7I FICHER } \\
\text { O NOTICIA 36203.pdf }\end{array}$ \\
\hline $\begin{array}{l}\text { Comentario para } \\
\text { la traducción }\end{array}$ & \\
\hline
\end{tabular}

\begin{tabular}{|l|l|}
\hline DE & Gar schlechter sich fühlen \\
\hline ES & empeorar \\
& \\
\hline $\begin{array}{l}\text { Definición } \\
\text { la traducción }\end{array}$ & \\
\cline { 2 - 2 } & \\
\hline
\end{tabular}

\begin{tabular}{|l|l|}
\hline DE & Hersteller \\
\hline ES & fabricante, responsable de la fabricación \\
& $\begin{array}{l}\text { Titular de la autorización en representación de quien la } \\
\text { persona cualificada ha cumplido con las obligaciones } \\
\text { específicas determinadas en el artículo 5I de dicha } \\
\text { Directiva; es decir, el fabricante responsable de la } \\
\text { liberación de cada lote en el mercado de la UE/EEE. Fuente: } \\
\text { Asociación Española de Derecho Farmacéutico } \\
\text { https://www.actasanitaria.com/fileset/doc_40I7I_FICHER } \\
\text { O_NOTICIA 36203.pdf }\end{array}$ \\
\hline $\begin{array}{l}\text { Comentario para } \\
\text { la traducción }\end{array}$ & \\
\hline
\end{tabular}




\begin{tabular}{|l|l|}
\hline DE & Name des Arzneimittels \\
\hline Definición & Denominación \\
& $\begin{array}{l}\text { Nombre genérico asignado por la OMS (Organización } \\
\text { Mundial de la Salud) para toda nueva molécula con } \\
\text { actividad terapéutica. La OMS asigna la DCl tras un } \\
\text { procedimiento exhaustivo de consultas a nivel mundial. }\end{array}$ \\
Fuente: Asociación Española de Derecho Farmacéutico \\
https://www.actasanitaria.com/fileset/doc 40I7I FICHER \\
O NOTICIA 36203.pdf \\
\hline $\begin{array}{l}\text { Comentario para } \\
\text { la traducción }\end{array}$ \\
$\begin{array}{l}\text { También lo podemos encontrar en otros textos del ámbito } \\
\text { como Denominación Común Internacional o bajo la sigla } \\
\text { D.C.I o E.O.E. En el prospecto tan solo está permitido la } \\
\text { forma denominación. Igualmente solo se permite el uso de } \\
\text { las siglas mencionadas en la ficha técnica en el apartado de } \\
\text { composición. }\end{array}$
\end{tabular}

\begin{tabular}{|l|l|}
\hline DE & Nebenwirkung \\
\hline Eefinición & $\begin{array}{l}\text { Cualquier experiencia indeseable relacionada con el uso de } \\
\text { un medicamento o de otro producto médico. Fuente: } \\
\text { infoSIDA } \\
\text { aids/glossary/4I06/efecto-adverso }\end{array}$ \\
\hline $\begin{array}{l}\text { Comentario para debemos confundir la denominación efecto adverso y } \\
\text { la traducción }\end{array}$ & $\begin{array}{l}\text { No decto secundario, ya que ambas coinciden en que son } \\
\text { manifestaciones producidas por la acción fundamental de } \\
\text { un medicamento que se producen de manera no } \\
\text { intencionada. Pero, la diferencia entre la primera } \\
\text { denominación y la segunda es el hecho de que efecto } \\
\text { adverso es perjudicial y el efecto secundario no lo es. }\end{array}$ \\
\hline
\end{tabular}

\begin{tabular}{|c|c|}
\hline DE & örtlicher Vertreter des pharmazeutischen Unternehmer \\
\hline ES & $\begin{array}{l}\text { Representante local del titular de la autorización de } \\
\text { comercialización }\end{array}$ \\
\hline \multicolumn{2}{|l|}{ Defínición } \\
\hline $\begin{array}{l}\text { Comentario para } \\
\text { la traducción }\end{array}$ & \\
\hline
\end{tabular}




\begin{tabular}{|l|l|}
\hline DE & Packungsbeilage \\
\hline Definición & prospecto \\
\hline $\begin{array}{l}\text { Papel o folleto que acompaña a ciertos productos, } \\
\text { especialmente los farmacéuticos, en el que se explica su } \\
\text { composición, utilidad, modo de empleo, etc. Fuente: DRAE } \\
\text { https://dle.rae.es/?id=UQfodPD }\end{array}$ \\
$\begin{array}{l}\text { Comentario para } \\
\text { la traducción }\end{array}$ & \\
\hline
\end{tabular}

\begin{tabular}{|l|l|}
\hline DES & Phantasiebezeichnung \\
\cline { 2 - 2 } Definición & denominación de fantasía \\
& $\begin{array}{l}\text { Denominación de un medicamento que no se corresponde } \\
\text { con una denominación común o científica acompañada de la } \\
\text { de una marca comercial o del nombre del titular de la } \\
\text { autorización de comercialización. } \\
\text { Ejemplo: Dormidina (denominación de fantasía). } \\
\text { Doxilamina (denominación) } \mathbf{2 5} \mathbf{~ m g}\end{array}$ \\
& $\begin{array}{l}\text { Fuente: en génerico https://www.engenerico.com/como-se- } \\
\text { identifican-los-medicamentos-en-espana/ }\end{array}$ \\
\hline Comentario para & \\
\hline la traducción
\end{tabular}

\begin{tabular}{|l|l|}
\hline $\begin{array}{l}\text { DE } \\
\text { ES }\end{array}$ & \multicolumn{4}{l|}{ Pharmazeutischer Unternehmer } \\
\hline Definición & $\begin{array}{l}\text { titualr de la autorización de comercialización } \\
\text { ca persona física o jurídica responsable de la } \\
\text { comercialización del medicamento para el que ha obtenido } \\
\text { la preceptiva autorización de comercialización. Fuente: } \\
\text { AEMPS } \\
\text { https://www.aemps.gob.es/industria/regLabFarma/home.htm }\end{array}$ \\
\hline $\begin{array}{l}\text { Comentario para } \\
\text { la traducción }\end{array}$ & $\begin{array}{l}\text { También lo podemos encontrar en otros textos del mismo } \\
\text { ámbito bajo la sigla TAC. En el prospecto tan solo está } \\
\text { permitido la forma Titular de la autorización de } \\
\text { comercialización. }\end{array}$ \\
\hline
\end{tabular}




\begin{tabular}{|c|c|}
\hline DE & seltene Erkrankung \\
\hline ES & Enermedad rara \\
\hline Definición & $\begin{array}{l}\text { Las enfermedades raras (ER) o poco frecuentes son } \\
\text { aquellas que tienen una baja prevalencia en la población. } \\
\text { Para ser considerada como rara, cada enfermedad } \\
\text { específica sólo puede afectar a un número limitado de } \\
\text { personas. Concretamente, cuando afecta a menos de } 5 \text { de } \\
\text { cada } 10.000 \text { habitantes. Fuente: feder (Federación Española } \\
\text { de Enfermedades Raras) } \underline{\text { https://enfermedades- }} \\
\text { raras.org/index.php/enfermedades-raras }\end{array}$ \\
\hline $\begin{array}{l}\text { omentario para } \\
\text { traducción }\end{array}$ & \\
\hline
\end{tabular}

\begin{tabular}{|l|l|}
\hline DE & Stärke \\
\hline ES & dosis \\
Definición & $\begin{array}{l}\text { Cantidad de principio activo que contiene cada forma } \\
\text { farmacéutica de un medicamento. Fuente: propia. }\end{array}$ \\
\hline $\begin{array}{l}\text { Comentario parán se } \\
\text { la traducción }\end{array}$ & $\begin{array}{l}\text { En el contexto del prospecto dos palabras en alemán se } \\
\text { traducen de la misma forma en español, como es el caso de } \\
\text { Stärke y Dosis que ambas se traducen por dosis. En el } \\
\text { segundo caso, el término se refiere según la Enciclopedia } \\
\text { médica y terminologia médica a la cantidad de fármaco que } \\
\text { se administra para el tratamiento de una enfermedad. } \\
\text { (https://www.diccionariomedico.net/diccionario- } \\
\text { terminos/645I-dosis) }\end{array}$ \\
\hline
\end{tabular}

\begin{tabular}{|l|l|}
\hline $\begin{array}{l}\text { DE } \\
\text { ES }\end{array}$ & Stillen \\
\hline $\begin{array}{l}\text { Definición } \\
\text { Comentario para } \\
\text { la traducción }\end{array}$ & $\begin{array}{l}\text { Su traducción literal sería dar el pecho, pero en español la } \\
\text { convención en este contexto es período de lactancia. }\end{array}$ \\
& $\begin{array}{l}\text { Ej. Wenn Sie schwanger sind oder stillen... } \\
\text { embarazada o en periodo de lactancia... }\end{array}$ \\
\hline
\end{tabular}




\begin{tabular}{|l|l|}
\hline DE & Tablette \\
\hline $\begin{array}{l}\text { ES } \\
\text { Definición }\end{array}$ & comprimido \\
$\begin{array}{l}\text { Comentario para } \\
\text { la traducción }\end{array}$ & $\begin{array}{l}\text { La traducción más usual para Tablette es pastilla pero en } \\
\text { este contexto siempre debe traducirse por comprimido. }\end{array}$ \\
\hline
\end{tabular}

\begin{tabular}{|c|c|}
\hline DE & verschrieben \\
\hline ES & recetar \\
\hline Definición & $\begin{array}{l}\text { Prescribir un medicamento, con expresión de sus dosis, } \\
\text { preparación y uso. } \\
\text { https://dle.rae.es/?id=VPyuiuy }\end{array}$ \\
\hline $\begin{array}{l}\text { Comentario para } \\
\text { la traducción }\end{array}$ & \\
\hline
\end{tabular}

\begin{tabular}{|l|l|}
\hline DE & Vorsichtsmaßnahme \\
\hline ES & precaución \\
\hline Definición & $\begin{array}{l}\text { Reserva, cautela para evitar o prevenir los inconvenientes, } \\
\text { dificultades o daños que pueden temerse. Fuente: DRAE } \\
\text { https://dle.rae.es/?id=Tuj/WIL }\end{array}$ \\
\hline $\begin{array}{l}\text { Comentario para } \\
\text { la traducción }\end{array}$ & \\
\hline
\end{tabular}

\begin{tabular}{|l|l|}
\hline DE & Warnhinweis \\
\hline Definición & advertencia \\
& $\begin{array}{l}\text { Escrito, por lo común breve, con que en una obra o en una } \\
\text { publicación cualquiera se advierte algo al lector. Fuente: } \\
\text { DRAE https://dle.rae.es/?id=0s/9iEl }\end{array}$ \\
\hline $\begin{array}{l}\text { Comentario para } \\
\text { la traducción }\end{array}$ & \\
\hline
\end{tabular}




\begin{tabular}{|l|l|}
\hline $\begin{array}{l}\text { DE } \\
\text { ES }\end{array}$ & Wirkstoff \\
\cline { 2 - 2 } Definición & $\begin{array}{l}\text { Principio activo } \\
\text { Componente responsable de las propiedades } \\
\text { farmacológicas o tóxicas de una sustancia. Fuente: DRAE } \\
\text { https://dle.rae.es/?id=UC5uxwk }\end{array}$ \\
\hline $\begin{array}{l}\text { Comentario para } \\
\text { la traducción }\end{array}$ & \\
\hline
\end{tabular}

Además de este glosario terminológico aplicado a las imágenes 1 y 2 mostradas con anterioridad, también hemos recogido en nuestro estudio la fraseología propia de este género textual. Para ello, hemos analizado un texto más en cada lengua de trabajo; así, en español se ha optado por un prospecto de comprimidos de amoxicilina/ácido clavulánico $875 \mathrm{mg} / 125 \mathrm{mg}$ de la farmacéutica Aurobindo $y$ en alemán se ha elegido un prospecto de comprimidos de acetilcisteína $6000 \mathrm{mg}$ de la farmacéutica Hexal. El resultado del estudio de la fraseología es el que recoge la siguiente tabla:

Tabla I: Glosario bilingüe DE-ES de fraseología propia del prospecto.

\begin{tabular}{|l|l|}
\hline \multicolumn{1}{|c|}{ DE } & \multicolumn{1}{|c|}{ ES } \\
\hline $\begin{array}{l}<\text { Wenn Sie eine größere Menge von X } \\
\text { <eingenommen> } \\
\text { haben, als Sie sollten }\end{array}$ & Si <toma><usa> más X del que debe \\
\hline Anwendung bei & Uso en \\
\hline $\begin{array}{l}\text { aufgrund der Seltenheit dieser } \\
\text { Erkrankung }\end{array}$ & debido a la rareza de su enfermedad \\
\hline aus ethischen Gründen & Por razones éticas \\
\hline aus wissenschaftlichen Gründen & Por motivos científicos \\
\hline Außergewöhnlichen Umständen & circunstancias excepcionales \\
\hline Besonderen Bedingungen & Aprobación condicional \\
\hline $\begin{array}{l}\text { Bewahren Sie dieses Arzneimittel für } \\
\text { Kinder unzugänglich auf. }\end{array}$ & $\begin{array}{l}\text { Mantener este medicamento fuera de la } \\
\text { vista y del alcance de los niños. }\end{array}$ \\
\hline $\begin{array}{l}\text { Bezeichnung gn+ sonstigen } \\
\text { Bestandteil }\end{array}$ & Nombre del excipiente \\
\hline
\end{tabular}




\begin{tabular}{|c|c|}
\hline $\begin{array}{l}\text { Das Verfalldatum bezieht sich auf den } \\
\text { letzten Tag des angegebenen Monats }\end{array}$ & $\begin{array}{l}\text { La fecha de caducidad es el último día } \\
\text { del mes que se indica.> }\end{array}$ \\
\hline Die empfohlene Dosis beträgt... & comendada es... \\
\hline $\begin{array}{l}\text { Diese Packungsbeilage wurde zuletzt } \\
\text { überarbeitet im }<\{\text { MM. } . J j\}\}><\text { Monat } \\
J J J\}>\text {. }\end{array}$ & $\begin{array}{l}\text { Fecha de la última revisión de este } \\
\text { prospecto: } \\
\text { AAAA }\}>\end{array}$ \\
\hline $\begin{array}{lll}\text { Durch/lesen die } & \text { gesamte } \\
\text { Packungsbeilage sorgfälting } & \end{array}$ & Leer \\
\hline $\begin{array}{l}\text { Inhalt der Packung und weitere } \\
\text { Informationen }\end{array}$ & $\begin{array}{l}\text { Contenido del envase e información } \\
\text { adicional }^{20}\end{array}$ \\
\hline Kind & Niños y adolescentes \\
\hline $\begin{array}{l}\text { Medizinische Fachpersonal } \\
\text { a. (....wenden Sie sich an Ihren Arzt, } \\
\text { oder Apotheker oder das } \\
\text { medizinische Fachpersonal), } \\
\text { (...wenden Sie sich an Ihren Arzt, } \\
\text { oder Apotheker oder das } \\
\text { medizinische Fachpersonal....) }\end{array}$ & $\begin{array}{l}\text { Consulte a su médico, farmacéutico o } \\
\text { enfermero }\end{array}$ \\
\hline $\begin{array}{l}\text { Schwangerschaft <und }><,>\text { Stillzeit } \\
<\text { und Fortpflanzungsfähigkeit }\end{array}$ & $\begin{array}{l}\text { Embarazo } \quad<y><,> \\
\text { fertilidad }>^{22}\end{array}$ \\
\hline $\begin{array}{l}\text { sichtbare Anzeichen } \\
\text { Nichtverwendbarkeit }\end{array}$ & indicios visibles de deterioro \\
\hline Verkehrstüchtigkeit und Fähigkeit zum & Conducción y uso de máquinas ${ }^{23}$ \\
\hline
\end{tabular}

20 La estructura morfosintáctica cambia del alemán al español, pasando uno de los títulos de los apartados del prospecto de interrogación directa a sintagma nominal que describe la información que se ofrece

${ }^{21}$ a. Su traducción literal sería personal médico especializado, pero en español la convención en este contexto es enfermero. (...consulte a su médico, o farmacéutico, o enfermero.).

${ }^{22}$ Se observa como Fortpflanzungsfähigkeit cuya traducción literal sería capacidad para la reproducción enmarcado en una unidad fraseológica se traduce por fertilidad, a pesar de que no sea el sustantivo Fertilität.

${ }^{23}$ Su traducción literal sería capacidad para conducir y manejar máquinas, pero en español la convención en este contexto es conducción y uso de máquinas 


\begin{tabular}{|c|c|}
\hline Bedienen von Maschinen & \\
\hline Was in dieser Packungsbeilage steht & Contenido del prospecto ${ }^{24}$ \\
\hline $\begin{array}{l}\text { Was ist } X \text { und wofür wird es } \\
\text { angewendet? }\end{array}$ & Qué es $X$ y para qué se utiliza ${ }^{25}$ \\
\hline $\begin{array}{l}\text { Was sollten Sie vor der <Einnahme }> \\
<\text { Anwendung }>\text { von } X \text { beachten? }\end{array}$ & $\begin{array}{c}\text { Qué necesita saber antes de empezar a } \\
\qquad<\text { tomar }><\text { usar }>X^{26}\end{array}$ \\
\hline Was X enthält & Composición de $\mathrm{X}^{27}$ \\
\hline $\begin{array}{l}\text { Welche Nebenwirkungen sind } \\
\text { möglich? }\end{array}$ & Posibles efectos adversos ${ }^{28}$ \\
\hline $\begin{array}{l}\text { Wie ist } \mathrm{X}<\text { einzunehmen }> \\
<\text { anzuwenden }>\text { ? }\end{array}$ & Cómo <tomar $><$ usar $>X^{29}$ \\
\hline Wie ist $X$ aufzubewahren? & Conservación de $\mathrm{X}^{30}$ \\
\hline Wie $X$ aussieht und Inhalt der Packung & $\begin{array}{c}\text { Aspecto del producto y contenido del } \\
\text { envase }\end{array}$ \\
\hline Zusätzliche Nebenwirkungen bei & $\begin{array}{l}\text { Experimentar cualquier tipo de efecto } \\
\text { adverso }\end{array}$ \\
\hline
\end{tabular}

\section{Conclusiones}

De todo lo expuesto en los epígrafes precedentes es posible colegir la relevancia del prospecto de medicamento como género textual dentro del ámbito de la traducción biosanitaria, debido a la relevancia económica del sector

${ }^{24}$ Se observa cómo la fraseología cambia del alemán al español pasando uno de los títulos de los apartados del prospecto de interrogación directa a sintagma nominal que describe la información que se ofrece.

${ }^{25}$ Se observa cómo la fraseología cambia del alemán al español pasando uno de los títulos de los apartados del prospecto de interrogación directa a indirecta.

${ }^{26}$ Se observa cómo la fraseología cambia del alemán al español pasando uno de los títulos de los apartados del prospecto de interrogación directa a indirecta.

27 Se observa cómo la fraseología cambia del alemán al español pasando uno de los títulos de los apartados del prospecto de interrogación directa a sintagma nominal que describe la información que se ofrece.

28 Se observa cómo la fraseología cambia del alemán al español pasando uno de los títulos de los apartados del prospecto de interrogación directa a sintagma nominal que describe la información que se ofrece.

${ }^{29}$ Se observa cómo la fraseología cambia del alemán al español pasando uno de los títulos de los apartados del prospecto de interrogación directa a indirecta.

30 Se observa cómo la fraseología cambia del alemán al español pasando uno de los títulos de los apartados del prospecto de interrogación directa a sintagma nominal que describe la información que se ofrece.

Futhark I 2 (20 I 7$)$ 
farmacéutico y en la forma en la que las compañías de dicho sector gestionan la traducción de este texto. En el pasado, las grandes compañías contaban con su propio servicio de traducción interno, pero con el paso del tiempo se ha tendido a la externalización de esta actividad. Esto hace que la demanda de empresas, agencias y traductores autónomos especializados en este tipo de texto aumente sin parar, lo que a su vez hace que su importancia y valor dentro de las aulas también lo haga, ya que de esta forma se formaría a los futuros profesionales de la traducción de acuerdo a las demandas del mercado del que van a formar parte.

En lo referente al análisis de la macroestructura del prospecto, observamos como esta se encuentra normativizada por el QRD que se ha encargado de elaborar un documento en el que se recogen todos los apartados que por ley debe tener, no quedando así lugar para omitir o añadir más información. Asimismo, vemos como cada elemento que forma parte de la macroestructura está regulado gracias a la labor del QRD y de la EMA, existiendo numerosos documentos que nos informan sobre cómo expresar las unidades de medida, qué abreviaturas se permiten y cuáles no, etc.

Centrándonos en el análisis de su terminología y fraseología, en el caso de los términos se ha registrado un mayor número de entradas con 46 que en el registro de la fraseología que se ha recogido un total de 28 entradas. Volviendo al análisis de los términos, en el glosario que se ofrece en la Tabla I podemos encontrar términos cuya inclusión es relevante a la hora de saber qué forma es la correcta de entre las diferentes disponibles para su traducción, como puede ser el caso de Tablette que no se puede traducir por pastilla, sino por comprimido; el verbo conservar que se expresa en alemán en el prospecto como aufbewahren y no con otras opciones, como podría ser solo bewahren o el caso de Bruchkerbe/Kerbe que se traducen de la misma forma al español por ranura. Asimismo, se han registrado términos y USE con una grado de especialización alto o medio como es el caso de medicamento sujeto a seguimiento adicional, medicamento huérfano, dosis farmacéutica, responsable de la fabricación, representante local del titular de la autorización de comercialización o titular de la autorización de comercialización. En el análisis de la fraseología advertimos como es común el cambio de interrogativa directa en alemán pasa a indirecta en español, sirva como ejemplo Was ist $X$ und wofür wird es angewendet? en alemán y Qué es $X$ y para qué se utiliza en español, o directamente la interrogativa directa en alemán se convierte en un predicativo en español: Wie ist $X$ aufzubewahren? en alemán y Conservación de $X$ en español.

Por último, consideramos que el objeto de estudio del presente trabajo -el prospecto- en la combinación lingüística alemán-español y desde un punto de vista traductológico podría resultar de gran utilidad para los ya profesionales de la traducción que aborden este tipo de textos, así como también para aquellos docentes que decidan integrar la traducción del prospecto en sus clases y por ende para sus estudiantes. 
Referencias bibliográficas

AEMPS. (2008). Información sobre los excipientes en el etiquetado, prospecto y ficha técnica de los medicamentos de uso humano. Circular número 2/2008. Disponible en: hutps//unwwaemps.gob.es/informa/circulares/medicamentosUsol_umano/2008/docs/dircular_022008 instruccion-excipientespdf [Consulta: 24/03/2017].

. (20II). Procedimiento para la presentación de las traducciones de fichas técnicas, etiquetado y prospectos de nuevas autorizaciones y variaciones de medicamentos por procedimiento descentralizado y reconocimiento mutuo. Nota informativa 9 de agosto de 201I. Disponible en: https://www.aemps.gob.es/industria/etiquetado/PreguntasRespuestas/home. htm\#abreviaturas [Consulta: 10/03/2017].

(2016). Registro de Laboratorios Farmacéuticos. Disponible en: https://www.aemps.gob.es/industria/regLabFarma/home.htm [Consulta: I0/ 03/2017].

Agencia Europea de Medicamentos. (2009). QRD Recommendations on the Expression of Strength in the Name of Centrally Authorised Human Medicinal Products. Disponible en: https://www.ema.europa.eu/en/documents/regulatoryprocedural-guideline/quality-review-documents-recommendations-

expression-strength-name-centrally-authorised-human_en.pdf [Consulta: 20/04/2017].

(2009). Guideline on the Readability of the Labelling and Package Leaflet of Medicinal Products for Human Use. Disponible en: https://ec.europa.eu/health/sites/health/files/files/eudralex/vol2/c/2009 0I_12 readability guideline_final_en.pdf [Consulta: 20/04/2017]. (2009). Compilation of QRD decisions on stylistic matters in product information. Disponible en: https://www.ema.europa.eu/documents/regulatoryprocedural-guideline/compilation-quality-review-documents-decisionsstylistic-matters-product-information en.pdf [Consulta: 20/04/20I7].

(2009). Ficha técnica o resumen de las características del producto. Disponible en: https://www.ema.europa.eu/documents/templateform/quality-review-documents-veterinary-product-information-templateversion-8I-es-pt-updated-07/0I/2019 es.doc [Consulta: 20/04/2017].

Alarcón, E. (1998). Variedad y especific/idad de la traducción médica. En Félix Hernández, L y Ortega Arjonilla, E. (eds.). II Estudios sobre Traducción e Interpretación, tomo 2. Málaga: Universidad de Málaga, 1025-1034.

Asociación Española de Derecho Farmacéutico. (2007). La redacción del prospecto. Recomendaciones para mejorar su comprensión. Disponible en: https://www.actasanitaria.com/fileset/doc_40I7I_FICHERO_NOTICIA_36 203.pdf [Consulta: I4/04/20I7]. 
Comisión Europea. (2009). Guideline on the Readability of the Labelling and Package Leaflet of Medicinal Products for Human Use. Disponible en: https:/lec.europa.eu/health//sites/health/files/files/eudralex/vol2/c/2009 0I 12 readability guideline final en.pdf [Consulta: 17/03/2017].

Durieux, C. (1998). La didactique de la traduction médicale. En Félix Hernández, L y Ortega Arjonilla, E. (eds.). Traducción e Interpretación en el ámbito biosanitario. Granada: Comares, 59-78.

Enciclopedia médica y terminologia médica. Disponible en: https://www.diccionariomedico.net/ [Consulta: 20/04/2017].

Ezpeleta, P. (20I2). An example of Genre Shift in the Medical Product Information Genre System. Lingüística Antverpiensia, II, I39- 159.

Félix, L y Ortega, E. (1998). Traducción e interpretación en el ámbito biosanitario. Granada: Comares.

Franco, J. (2010). Una revisión bibliográfica sobre traducción e interpretación médica recogida en BITRA (Bibliografía de Interpretación y Traducción). Panace@, II, 3, I5I-I60.

García, A.I y Varela, M. J. (2009). Propuesta de una unidad didáctica de traducción biosanitaria alemán-español. En Varela Salinas, M.J (ed.). Panorama actual del estudio y la enseñanza de discursos especializados. Berna: Peter Lang, I23144.

Gouadec, D. (2007). Translation as a Profession. Ámsterdam/Filadelfia: John Benjamins.

Hernández, F. (1998). El servicio de traducción de una compañía farmacéutica multinacional. En Félix, L y Ortega, E. (eds.). Traducción e Interpretación en el ámbito biosanitario. Granada: Comares, I37-I42.

Hurtado, A. (200I). Traducción y Traductología. Introducción a la Traductología. Madrid: Cátedra.

Mayor, M. B. et al. (2004). ¿Y ahora qué? Salidas profesionales del traductor médico? Panace@, 5, I6, 127-134.

Mayor, M. B. (2012). La iformación de traductores médicos? Sugerencias didácticas. Panace@,6, 20, 132-|4I.

Montalt i Resurrecció, V. (2009). La consulta documental y humana aplicada a la traducción médica: reflexiones en torno a la práctica profesional y a la pedagogía. En M. Pinto et al (eds.). Documentación aplicada y Espacio Europeo de Educación Superior. Madrid: Arco Libros, 171-185.

(2010). Medical translation and inteprreting. En Gambier, Y y van Doorslaer L. (eds.). Handbook of Translation Studies, volumen 2. Amsterdam/Filadelfia: John Benjamins, 79-82.

Montalt i Resurrecció, V. y González, M. (2007). Medical Translation Step by Step. Learning by Drafting. Mánchester/Kinderhook: St. Jerome. 
Montalt Resurrecció, V y Shuttleworth, M. (2012). Research in Translation and Knowledge Meditation in Medical and Healthcare Settings. Lingüística Antverpiensa, II, 9-29.

Múñoz-Miquel, A. (2016). La traducción médica como especialidad académica: algunos rasgos definitorios. Hermeneus, 18, 235-267.

Navarro, F.A y Hernández, F. (1997). Anatomía de la traducción médica. En Félix Hernández, L y Ortega Arjonilla, E. (eds.). Lecciones de teoría y práctica de la traducción. Málaga: Universidad de Málaga, I37-162.

Navascués, I y Hernando, A. (1998). El médico traductor de textos médicos. En Félix, L. y Ortega, E. (eds.). Traducción e Interpretación en el ámbito biosanitario. Granada: Comares, I47-I58.

Orf, D. (2005). Estudio de situación del mercado español de servicios profesionales de la traducción. Madrid: Agrupación de Centros Especializados en Traducción.

Rouleau, M. (20I2). La traduction médicale. Une approche méthodique. Montreal/Quebec: Linguatech.

Steiert, A y Steiert, M. (20II). Medical Translation Basics. Multilingual, July/August, 27-28.

Unión Europea. Directiva (UE) 2001/83 del Consejo, de 6 de noviembre de 2001, que establece un código comunitario sobre medicamentos para uso humano. Diario Oficial de las Comunidades Europeas $L 311 / 67,28$ de noviembre de 200 I.

. Directiva (UE) 2004/27 del Consejo del 31 de marzo de 2004, que modifica la Directiva 2001/83 en lo que respecta al código comunitario sobre medicamentos para uso humano. Diario Oficial de las Comunidades Europeas L 136/34, 30 de abril de 2004.

Vázquez, E. (2006). La redacción del discurso biomédico (inglés-español): rasgos principales. Panace@, 7,24, 307-3I7.

Ximénez, L. (2017). 2016, año de crecimientos generalizados para el sector farmacéutico. PMFarma, 23 enero de 2017. Disponible en: http://pmfarma.es/noticias/23855-2016-ano-de-crecimientos-generalizadospara-el-sector-farmaceutico.html [Consultado: 5 febrero de 2017].

Yates, J y Orlikowski, W. (2002). Genre Systems: Structuring Interaction thorough Communicative Norms. Journal of Business COmmunications, 39, I, I 3-35. 